\title{
LOS CAÑONES DE CARLOS V
}

\author{
POR \\ NARCISO SANCHEZ MORALES
}

LA artillería, o la artollerey, como la designaban los pueblos de Centroeuropa allá en el Medievo, comprendía toda la gama de ingenios de guerra para el asedio de plazas, una progresión, evolutiva, de las antiguas catapultas, artefactos y máquinas de herrería. En el siglo Xrv se convierte en cañón el Kanone o Kartaune germano, que creemos que, etimológicamente, se deriva de la palabra latina canna o caña, aunque existen quienes lo hagan provenir del bajo alemán Kanne o del vocablo flamenco quenne.

Vamos a sujetarnos a la evolución que sufre en España a partir del Medievo, si bien con Carlos $\mathrm{V}$ tengamos que fusionarnos con la artillería imperante en toda Europa, ya que nuestro César, como lo hicieran los Reyes Católicos y el mismo Cisneros, tuvo que acudir a la incipiente industria militar que tenía sus principales fundiciones en Europa: Nüremberg, Augsburgo, Innsbruck y Estrasburgo.

$¿$ Fue Alfonso el Batallador, en el sitio de Zaragoza, el primero que echó mano de tales artefactos? ¿Fue Alfonso X, en el asedio de Niebla? Arántegui supone que fueron los moros los primeros que los emplearan en los sitios de Tarifa (1340) y Algeciras (1342) y que de ellos lo tomaron los cristianos para expugnar villas fortificadas y castillos. También los usaron los castellanos en sus expediciones al exterior, como en el sitio de la Rochela (1371) contra la escuadra inglesa, al mando de lord Pembroke. Los más primitivos fueron las bombardas o lombardas, conjunto de duelas de hierro forjados, unidos por arandelas de fino metal. En el siglo xv aparecen ya las cerbatanas y el mortero de tiro curvo, precursores de nuestro cañón de campaña: la espingarda y falconete, a la vez que hace su aparición el órgano, de cuatro o cinco bocas de fuego, digno antecesor de la actual ametralladora. A fines del xiv surgen en España las bombardas de bronce, y al siglo siguiente se funden ya cañones de una sola pieza, dotándoles de muñones y apoyados en cureñas para levantar o bajar la culata. Así, pues, al comenzar el siglo XVI, el siglo de Carlos V, tenemos tres tipos: la culebrina, para atacar al enemigo, propio de la infantería, que lo usa en sus variadas formas y nombres de dragón o doble culebrina, media culebrina, mosquetón, mosquete...; el cañón, en sus variedades de despertador, siflante, rebufo, berraco (para batir murallas), falcón, falconete, aspid, barrefosos, basiliscos, bastardo, batemuro, bombarda, culebrina..., y el mortero, para echar a pique naves de guerra. Fueron 
célebres el serpentín de Málaga, la culebrina de Milán o pimentel y los Doce Apóstoles, que mandó fundir Carlos V contra los Doce Pares de Francisco I. En la batalla de Pavía, la artillería imperial, a base de arcabuceros, destroza los escuadrones de Francisco I, y en la de Mühlberg se llegan a coger hasta 500 piezas. Queda, pues, como artillería principal en la época imperial la culebrina, el sacre y el falconete; la primera para batir; el segundo, como pieza de posición, y el tercero, como cañón de campaña. Las fundiciones eran del Estado y estaban situadas en Málaga, Burgos y Barcelona, dentro de España; pero en el exterior había que acudir, a base de los créditos de los Fugger, a sus propias funciones, sitas en Nüremberg, Augsburgo, Ulma y Viena, sin olvidar las de Milán, Utrecht e Innsbruck. Pero, en las campañas de Centroeuropa, los grandes proveedores se encontraban en Innsbruck - de ellos nos ocuparemos más adelante-, ya que Innsbruck, en manos de Fernando I y como punto de paso entre Italia y Alemania, era la ciudad más segura y centrada para los suministros del emperador.

El personal que servía a la artillería imperial estaba formado, en la cabeza, por los maestros bombarderos (aprendices, oficiales y maestros), de quienes dependían los sirvientes y todo el servicio de tracción con sus carros y mulas. A fines del XVI, se creará en España un capitán general de artillería, con dos o tres tenientes de capitán general, y un cuerpo de oficiales, ingenieros, tracistas y gentilhombres; la tropa se subdividía en artilleros, minadores y gastadores (zapadores).

Una de las fundiciones que más falconetes suministrara al emperador Carlos V fuera la de Mühlau, a las puertas de Innsbruck, y propiedad de Gregorio Löffler, así como igualmente son célebres los berracos, morteros y basiliscos que le proporcionara Leonardo Fronsperger, ciudadano de Ulma, una figura interesante de la época que bien le pudiéramos comparar a un Clausewitz, ya que a más de ser proveedor de la casa imperial, respaldado por la Banca de los Fugger, fue un jurídico militar, un dogmático de la guerra, con teorías que él ha dejado consignadas en su célebre libro Kriegsbuch.

Pero tornemos a las fundiciones tirolesas y a sus principales propulsores y fabricantes, los Löffler. No olvidemos que el emperador era nieto del gran Maximiliano I, que obtiene el Tirol del duque Segismundo el Rico. En el reinado de este duque, la minería tirolesa toma un gran incremento y proporciona gran cantidad de cobre para la construcción de cañones. Los centros mineros eran los de Schwaz y Taufers, y allá se desplazó del centro principal de la industria del latón, situada en Nüremberg, el empleado de la corte imperial y consejero de la misma Peter Rumel, que es el que termina con el monopolio del latón de aquella ciudad a base del cobre del Tirol. La riquísima fuente de cobre del Tirol 
será la base para las fundiciones artilleras de latón y bronce, ya que cinc y estaño abundaban por doquier, y además el bronce de los cañones contenía un 90 por 100 de cobre y un 10 por 100 de cinc, mientras en las campanas se reducía al 80 y 20 por 100 , respectivamente. Fue Segismundo quien, en 1460, con el artillero Widerstein, que trajera de Nüremberg, estableciera los talleres de Mühlau y Hötting en los contornos de Innsbruck. Sería luego Hans Seelos, ya bajo el mando de Maximiliano I, quien ampliara la industria artillera. Luego, bajo la dirección del artillero Offenhauser, monta una industria de latón para las armas de fuego de la infantería. También disponía el emperador de la fundición artillera de Estrasburgo, a cargo del innsbrucqués maestro Jörg Seelos. El

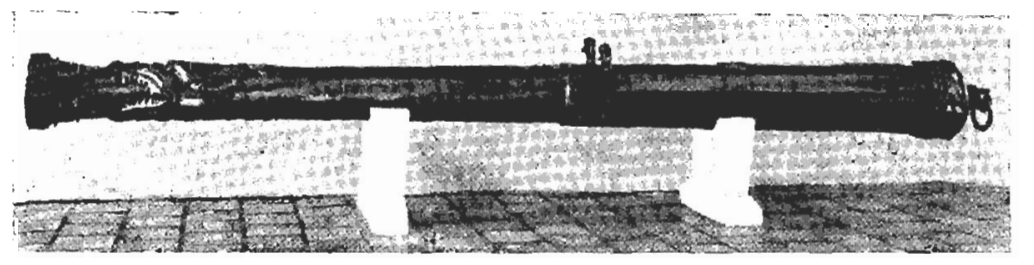

Basilisco «Dragón» de Jörg de Guntheim para Basilea. 1513-1514. (Museo Histórico de Basilea.)

libro de cañones de Carlos V (1550) muestra entre el botín cogido en la campaña de Esmalcalda culebrinas de Estrasburgo, de calibre 11,1 y 10,7, cuyo adorno, además de la cabeza de dragón, que sólo tenían los basiliscos, tenía la misma figura que el dragón basilense. Se construían tres tipos de

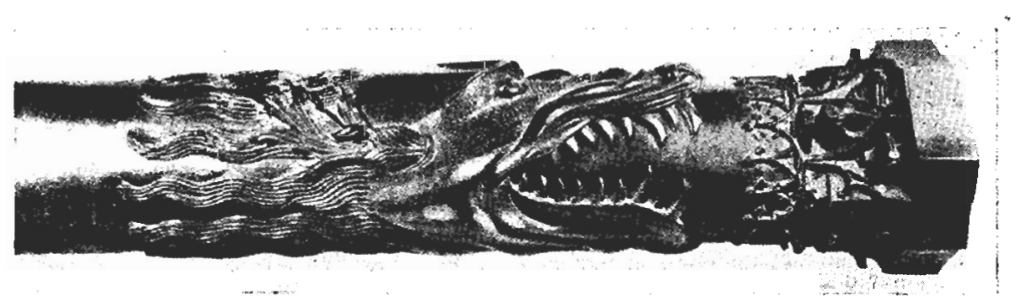

Basilisco «Dragón», su boca de fuego.

cañones: culebrinas, de pesado calibre, para romper muros; los falconetes, como artillería de acompañamiento de la infantería, y los morteros, con un subtipo más ligero llamado alcón. Cuidó mucho de los ornatos y leyendas que se grababan en la caña. 
Con Leiminger, que tomó el nombre de Peter Löffler, entra en las fundiciones de Innsbruck la familia proveedora de la artillería de Carlos V. La principal figura entre estos fundidores fue Gregorio Löffler, el segundo de los hijos de Peter, que construye cañones, alternativamente, en Augsburgo e Innsbruck. Recibe encargos no sólo del emperador, sino también de sus generales y jefes. Así, su hermano Felipe construye para Alfonso de Avalos, y él, para el conde de Feria y el duque de Alba, así como para el marqués de las Navas.

En este aspecto existe una anécdota muy curiosa, que dice mucho de la valentía fanfarrona del duque de Alba. Vamos a referirla, porque, además de lo divertida que resulta, nos confirma la construcción de arcabuces y cañones de los Löffler.

Corría el año de 1552, ya a alguna distancia de la victoria imperial de 1547, de la que participaron conjuntamente ambos hermanos, Carlos y Fernando, sobre los componentes de la Liga de Esmalcalda. Se encontraban ambos en la ciudad de Innsbruck, la capital del rey de romanos Fernando, cuando llegó a sus oídos la sorprendente noticia de la traición

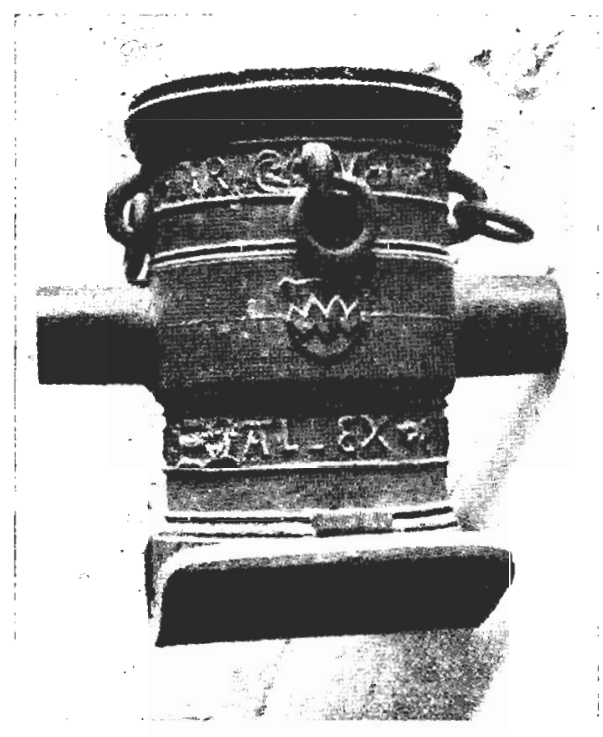

Mortero de Alejandro Endorfer. 1531. (Zenoburgo de Meran.)

del niño mimado del emperador, del duque Mauricio de Sajonia, a quien se había unido el joven Landgrave de Hessen. Las tropas imperiales, que acudieron con toda rapidez a Reutte, fueron derrotadas y el de Sajonia 
se apoderó del castillo de los Klausen Ehrenbergen, que estaba defendido por el castellano Friedrich von Hausen y por el fundidor Gregorio Löffler. No se pudo impedir que las fuerzas de Mauricio entraran en Innsbruck el 23 de mayo, teniendo que emprender precipitada fuga hacia el Sur tanto Fernando I como Carlos V. Pero durante el sitio del castillo que defendía Gregorio, su hijo Elías pudo acercarse secretamente a Mauricio y conseguir de él que no se robara nada de los almacenes y talleres de su padre, por lo que se transmitió una orden al Landgrave de Hessen para que respetara todo el material. Pero dado que la orden se basaba en que el señor de la tierra, Fernando I, no era beligerante en tal contienda, sino sólo su hermano Carlos, el Landgrave de Hessen y el duque de Mecklenburg se apoderaron de once falcones de quintales con sesenta libras de peso pertenecientes al emperador, de once falconetes del duque de Alba y de dos del mayordomo imperial Manrique. Entre el material que se apropiaron resultó interesante el del duque de Alba: el valiente y gallardo militar español, pero fanfarrón y presumido en la Corte de España, se había hecho fundir por Gregorio Löffler once falconetes con el ornato de las armas del de Hessen, para hacerlos pasar más tarde en Madrid como grandioso botín de la guerra anterior de Esmalcalda y como apresados al derrotado padre del joven Landgrave de Hessen. Ni qué decir tiene que el teutón se aprovechó de la fallida treta del de Alba y decidió llevárselos, porque dijo eran propios suyos, como la dedicación de los falconetes lo confirmaba. Todas las ctónicas tudescas se hicieton eco del suceso, e incluso la crónica imperial del conde Zimmern lo cita.

A propósito del caso, anotemos que tanto campanas, que también fabricaban los Löffler, como cañones, llevaban su partida de nacimiento con fechas, nombres de los fundidores, leyendas y ornatos de escudos

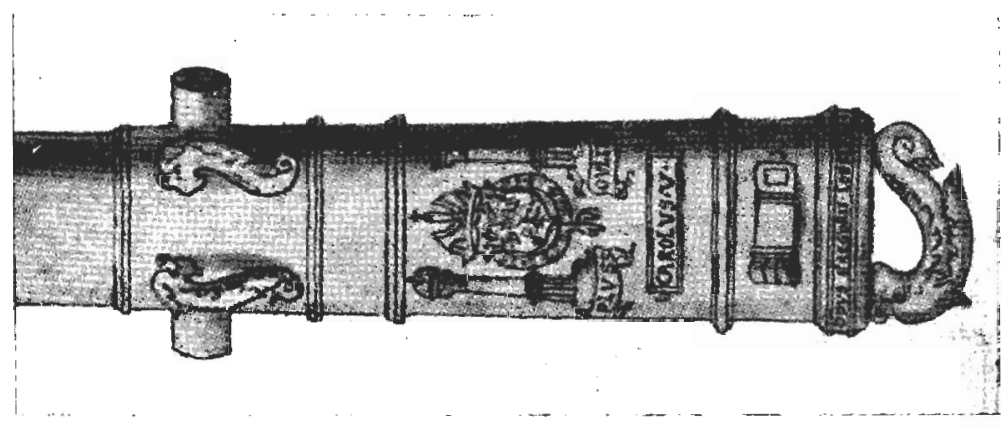

Cañón «Carolus V» de Gregorio Löffler. 1544-1545. (Libro de Cañones de Carlos V.) 
y animales. Así, nos encontramos en Simancas con el dibujo de un cañón de Löffler, en el segundo cuerpo de la caña varios delfines como asas, en el tercero el escudo imperial con el águila bicéfala sobre las columnas de Hércules y la banda del «Plus Ultra», debajo el nombre de Carolus y en la base de la misma la frase «Opus Gregorii Löefer Augustani.» «Es un cañón - aclara la cédula de identificación de Simancas - que tira cuarenta libras de pelota y pesa 29 quintales de Castilla y 30 libras; tiene de calibre 19 diámetros de calibo y 3 cuartos.»

En general, los cañones de Löffler llevan en la boca del mismo un friso ornamental a base de máscaras y bandas verticales de acanto, sigue luego la primera parte de la caña en forma lisa, la segunda o cuerpo medio con los dos delfines-asas típicos de los Löffler y la tercera con el escudo imperial, la banda «Plus Oultre» y el «Carolus» debajo, mientras en la base está inscrito el «Opus Gregorii Löefer». Es el modelo que repro-

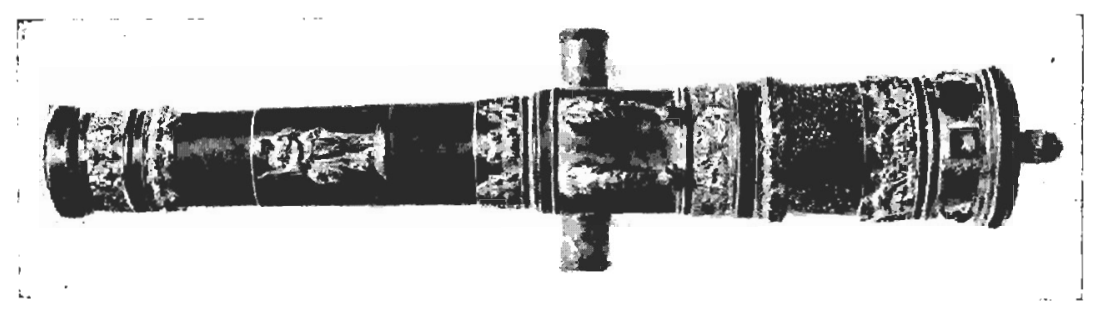

Modelo de un falconete fabricado en Nüremberg en 1550. (Museo de Arte e Industria de Hamburgo.)

ducimos y figura en el Libro de Cañones de Carlos V, que comprendía los propios y los arrebatados en la batalla de Esmalcalda, y que en su versión española lleva el título de «Discurso de Artillería del Invictis Emperador Carolo V... Anno 1550», una verdadera historia de la artillería y de su evolución en la primera mitad del siglo xvI.

Contiene la obra los dibujos y reseñas de los 149 cañones propios del emperador, con dos de los condes de Castillo y Pierrefort. Siguen luego los del botín de Esmalcalda: 170 del Landgrave de Hessen, 131 del Elector Juan Federico de Sajonia, 3 del Duque del Palatinado, 12, respectivamente, de las ciudades de Ulma, Augsburgo y Estrasburgo, 7 de Heilbronn, 5 de las ciudades de Ravensburgo y Hall suaba, 6 de Esslingen, 4 de Memmingen y 1 , respectivamente, de Reutlingen y Eisenach; en total, 520 piezas.

Como podrá verse, una numerosísima artillería; si la comparamos con aquella otra que Carlos V llevó consigo en su entrada en Valladolid en 
1522, que da Valdivielso y reproduce el Memorial Histórico del general Salas:

18 cañones de 17,5 de largo y 1 de boca.

16 serpentinos de 16 palmos de largo y 1 de boca.

1 bombarda de 10 palmos de larga y 2 de boca.

2 trabucos de 4 palmos y 2 de boca.

1 trabuco Magnus Draco de 26 palmos y 2 de boca.

2 tiros, la Pollina y el Pollino, de 16 palmos y 1,5 de boca.

1 tiro, «Espérame que allá voy», de 17 palmos y casi 2 de boca.

2 tiros, Santiago y Santiaguillo, de 26 palmos y 1 de boca.

1 tiro con el dibujo del emperador de 16 palmos y 1,5 de boca.

1 tiro, el Gran Diablo, de 18 palmos y 2 de boca.

En total, una artillería que sumaba unas 74 piezas.

En nuestro trabajo nos hemos limitado a la artillería del emperador en el campo de operaciones de Centroeuropa, donde estaba concentrada casi toda ella; pero habría que añadir la de posición en castillos, plazas fuertes y puertos fortificados, además de aquellos cañones o basiliscos que iban embarcados en la escuadra imperial y la ya numerosa de las Indias occidentales.

Nos hemos fijado más en lo europco, pues de Europa llegaban los fundidores y artificieros que trabajaban en las incipientes fábricas de armas de Málaga, Burgos y Barcelona, que eran las que aprovisionaban a las plazas españolas y a las expediciones que marchaban a las Indias. Pero de Alemania procedía lo mejor y más selecto de la artillería imperial: de Nüremberg, Augsburgo, Innsbruck y Estrasburgo.

\section{B I B L I O GR A F I A}

Aparici y GaRcía, José: Memorias históricas sobre el arte del ingeniero y del artillero en Italia desde su origen basta principios del siglo XIX (manuscrito en la antigua Biblioteca de Ingenieros. Vid. Bb. núm. 489).

ArÁntegui y SAnz, José: Apuntes bistóricos sobre la artillería española en los siglos XIV y XV. Madrid, 1887.

Barado, Francisco: Museo Militar. Historia del Ejército español. Tomo I. Barcelona, 1883.

Barrios, Cándido: Armas portátiles. Madrid, 1872.

EGG, Erich: Der Tiroler Gescbützguss (1400-1600). Innsbruck, 1961.

Salas, Ramón de: Memorial bistórico de la artillería española. Madrid, 1831. 